\title{
THREE DIMENSIONAL ANALYTICAL SEPARATION OF GRAIN BOUNDARY AND SURFACE SCATTERINGS IN POLYCRYSTALLINE METAL FILMS IN THE CASE OF NON CUBIC GRAINS
}

\author{
C. R. TELLIER $\dagger$, C. R. PICHARD and A. J. TOSSER \\ Laboratoire d'Electronique Université de NANCY - I C. O. 14054037 - NANCY-CEDEX \\ (France)
}

(Received July 30, 1980; in final form November 18, 1980)

\begin{abstract}
Analytical approximate expressions for the resistivity and its temperature coefficient of thin polycrystalline metal films have been derived by considering separately the contributions of the grain-boundaries perpendicular to the $x$-, $y$ - and $z$-axes. Provided that the grain-boundaries act as moderately efficient scatterers reasonable deviations from the three-dimensional model are obtained; an approximate model then seems convenient with which to perform the calculations of the strain coefficients of such fine-grained films.
\end{abstract}

\section{INTRODUCTION}

We have previously shown ${ }^{1}$ that to make more tractable the problem of evaluating the strain coefficients of infinitely thick polycrystalline films in terms of the three dimensional grain boundary model $^{2,3}$ it was convenient to consider the separate contributions of the three distributions of grain boundaries to the total film resistivity $\rho_{F p}$. In a similar manner when the film thickness ' $a$ ' becomes sufficiently thin so that the external surface scattering must be taken into account ${ }^{3}$ the problem of finding the strain coefficients of such thin polycrystalline films may be solved by calculating as a first step the three following contributions to the resistivity, i.e.:

a) the contribution $\rho_{\perp}$ of the grain-boundaries perpendicular simultaneously to the $x$-axis and to the applied electric field $E_{x}$ (Figure 1),

b) the contribution $\rho_{\|}$of the grain-boundaries parallel to the electric field $E_{x}$ and perpendicular to the $y$-axis,

c) the contribution $\rho^{*}$ due to the three following electron mechanisms occurring simultaneously, i.e. the scattering on the grain-boundaries perpendicular to the $z$-axis, the scattering at external surfaces and

†Laboratoire de Chronométrie et Piézoelectricité. E.N.S.M.M. Route de Gray - 25030 BESANCON-Cedex (France). the background scattering due to point defects and phonons.

In this communication an attempt is made to derive in this framework approximate expressions for both the total polycrystalline film resistivity and its temperature coefficient (t.c.r.) and then to determine the range of applicability of the relations.

\section{THEORETICAL}

\subsection{The total film resistivity $\rho_{F p}$}

It has been previously shown that the contributions $\rho_{\perp}$ and $\rho_{\|}$are respectively given by: $:^{1,4}$

$$
\begin{aligned}
& \rho_{\perp}=\rho_{0}\left\{\left[F\left(v_{x}\right)\right]^{-1}-1\right\} \\
& \rho_{/ /}=\rho_{0}\left\{\left[G\left(v_{y}\right)\right]^{-1}-1\right\}
\end{aligned}
$$

with

$$
F\left(v_{x}\right)=3 v_{x}\left\{\frac{1}{2}-v_{x}+v_{x}^{2} \ln \left(1+v_{x}^{-1}\right)\right\}
$$

and

$G\left(v_{y}\right)=\frac{3}{2} v_{y}\left\{v_{y}-\frac{1}{2}+\left(1-v_{y}^{2}\right) \ln \left(1+v_{y}^{-1}\right)\right\}$

where $\rho_{0}$ is the background resistivity.

The grain boundary parameter $v_{i}(i=x, y, z)$ is related as usual ${ }^{2,3,5}$ to the background mean free path $l_{0}$, the average grain size $a_{g}$ and the transmission coefficient $t$ of electrons through grain-boundaries, 


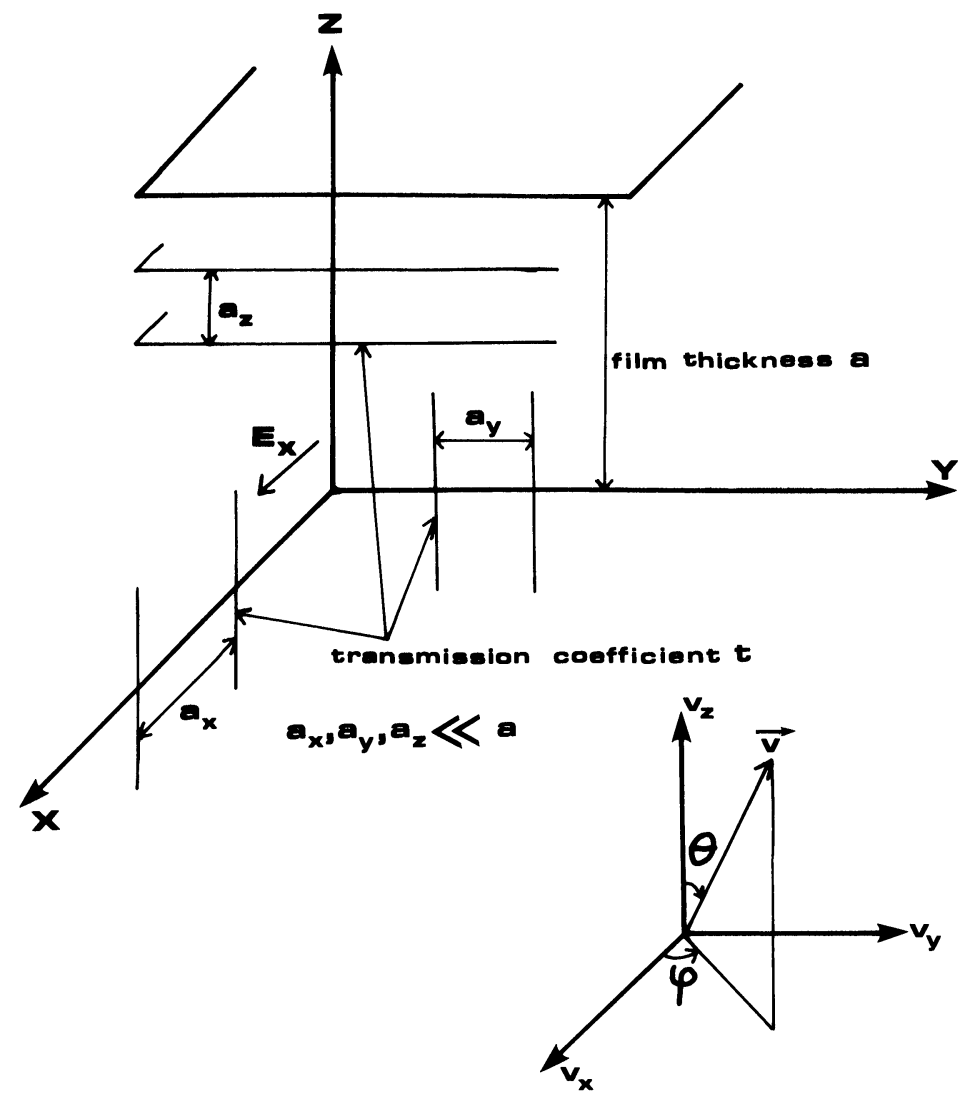

FIGURE 1 The geometry of the model.

by equation

$$
v_{i}=a_{i} \cdot l_{0}^{-1}\left[\ln \frac{1}{t}\right]^{-1}, i=x, \mathrm{y}, z
$$

To determine the contribution $\rho^{*}$ we suppose that the scattering events occur independently of each other so that the resultant mean free path $l^{*}$ is expressed as, ${ }^{3,6}$

$$
\frac{1}{l^{*}}=\frac{1}{l_{0}}+\frac{1}{l_{s}}+\frac{1}{l_{z}}
$$

the subscripts $s$ and $z$ referring respectively to external surface scattering and to electron scattering at the grain boundaries perpendicular to the $z$-axis.

The mean free path (m.f.p.) related to scattering at external surfaces $l_{s}$ is given as usual ${ }^{3,7}$ by

$$
l_{s}=\frac{a}{\left(\ln \frac{1}{p}\right) \cdot\left|\frac{v_{z}}{v}\right|}
$$

where $v_{z}$ is the $z$-component of the electron velocity and $p$, as defined earlier ${ }^{8}$, is the fraction of electron specularly scattered at external surfaces.

The m.f.p. $l_{z}$ describing the grain-boundaries scattering is found to be ${ }^{9}$

$$
l_{z}=\frac{a_{z}}{\left\{\ln \frac{1}{t}\right\} \cdot\left|\frac{v_{z}}{v}\right|}
$$

Introducing the spherical coordinates $(\psi, \phi, v)$ with $v_{z}=v \cos \theta$ and following the line of previous calculations the contribution $J_{x}^{*}$ to the total current density $J_{x}$ becomes for the geometry of the model (Figure 1)

$$
\begin{aligned}
J_{x}^{*}=\frac{2 e^{2} m^{2} v^{2} l_{0} E_{x}}{h^{3}} & \int_{0}^{2 \pi} \cos ^{2} \psi \mathrm{d} \psi \\
& \int_{0}^{\pi} \frac{\sin ^{3} \theta \mathrm{d} \theta}{1+\alpha^{-1}|\cos \theta|}
\end{aligned}
$$


with

$$
\alpha^{-1}=\mu^{-1}+v_{z}^{-1}
$$

In the preceding equation the external surface parameter is defined as: ${ }^{3,7}$

$$
\mu=a \cdot l_{0}^{-1} \cdot\left[\ln \frac{1}{p}\right]^{-1}
$$

Integration of Eq. (9) leads to

$$
\sigma^{*} / \sigma_{0}=G(\alpha)=\frac{3}{2} \alpha\left\{\alpha-\frac{1}{2}+\left(1-\alpha^{2}\right) \ln \left(1+\alpha^{-1}\right)\right\}
$$

where $\sigma_{0}$ is the background conductivity $\left(\sigma_{0}=\right.$ $\left.\left\{8 \pi e^{2} m^{2} v^{2} l_{0}\right\} / 3 h^{3}\right)$.

Assuming that Matthiessen's rule holds an approximate form of the total film resistivity is:

$$
\begin{gathered}
\rho_{F p} / \rho_{0}=\left[F\left(v_{x}\right)\right]^{-1}+\left[G\left(v_{y}\right)\right]^{-1}+[G(\alpha)]^{-1} \\
-2=M\left(v_{x}, v_{y}, \alpha\right)
\end{gathered}
$$

\subsection{The film t.c.r. $\beta_{F p}$}

One interesting way to analyze the range of validity of the present method before undertaking study of the strain coefficients is to derive an approximate formulation of the film t.c.r. from logarithmic differentiation of Eq. (13).

This gives after some mathematical manipulations:

$$
\begin{aligned}
& \frac{\mathrm{d} \rho_{F p}}{\rho_{F p}}-\frac{\mathrm{d} \rho_{0}}{\rho_{0}}=-\frac{1}{M\left(v_{x}, v_{y}, \alpha\right)}\left\{\frac{1}{F^{2}\left(v_{x}\right)} \cdot \frac{\mathrm{d} F\left(v_{x}\right)}{\mathrm{d} v_{x}} \mathrm{~d} v_{x}\right. \\
& \left.+\frac{1}{G^{2}\left(v_{y}\right)} \frac{\mathrm{d} G\left(v_{y}\right)}{\mathrm{d} v_{y}} \mathrm{~d} v_{y}+\frac{1}{G^{2}(\alpha)} \frac{\mathrm{d} G(\alpha)}{\mathrm{d} \alpha} \cdot \mathrm{d} \alpha\right\}
\end{aligned}
$$

Assuming, as usual,,$^{3,10,11}$ that the thermal coefficients of linear expansion of film thickness $a$ and grain size $a_{i}$ are negligible in regard with that of the bulk m.f.p. $l_{0}$, it yields:

$$
\frac{\mathrm{d} v_{i}}{v_{i}}=-\frac{\mathrm{d} l_{0}}{l_{0}}
$$

and

$$
\frac{\mathrm{d} \alpha}{\alpha}=-\frac{\mathrm{d} l_{0}}{l_{0}}
$$

Defining for convenience the functions

$$
\begin{aligned}
f\left(v_{i}\right)=\frac{\mathrm{d} F\left(v_{i}\right)}{\mathrm{d} v_{i}} & =\frac{3}{2}-6 v_{i}+9 v_{i}^{2} \ln \left(1+v_{i}^{-1}\right) \\
& -\frac{3 v_{i}^{2}}{1+v_{i}}
\end{aligned}
$$

and

$$
g(\alpha)=\frac{\mathrm{d} G(\alpha)}{\mathrm{d} \alpha}=\frac{3}{2}\left[3 \alpha-\frac{3}{2}+\left(1-3 \alpha^{2}\right) \ln \left(1+\alpha^{-1}\right)\right]
$$

leads to

$$
\begin{aligned}
\frac{\mathrm{d} \rho_{F p}}{\rho_{F p}} & =\frac{\mathrm{d} \rho_{0}}{\rho_{0}}+\frac{1}{M\left(v_{x}, v_{y}, \alpha\right)}\left(\frac{\mathrm{d} l_{0}}{l_{0}}\right)\left\{\frac{v_{x} f\left(v_{x}\right)}{F^{2}\left(v_{x}\right)}\right. \\
& \left.+\frac{v_{y} g\left(v_{y}\right)}{G^{2}\left(v_{y}\right)}+\frac{\alpha g(\alpha)}{G^{2}(\alpha)}\right\}
\end{aligned}
$$

Taking into account the definition of the t.c.r. $\beta^{11}$

$$
\beta=\mathrm{d} \ln \rho / \mathrm{d} T
$$

and assuming that the rigid band model of metal is valid and that the number of conduction electrons per unit volume is temperature independent the bulk t.c.r. $\beta_{0}$ is given by:

$$
\beta_{0}=\mathrm{d} \ln \rho_{0} / \mathrm{d} T=-\mathrm{d} \ln l_{0} / \mathrm{d} T
$$

The resultant t.c.r. $\beta_{F p}$ is then evaluated

$$
\begin{gathered}
\beta_{F p} / \beta_{0}=1-\frac{1}{M\left(v_{x}, v_{y}, \alpha\right)}\left\{\frac{v_{x} f\left(v_{x}\right)}{F^{2}\left(v_{x}\right)}+\frac{v_{y} g\left(v_{y}\right)}{G^{2}\left(v_{y}\right)}\right. \\
\left.+\frac{\alpha g(\alpha)}{G^{2}(\alpha)}\right\}
\end{gathered}
$$

When electron scattering at external surfaces becomes specular or when the film thickness becomes infinite the film t.c.r. $\beta_{F p}$ tends to the approximate grain-boundary t.c.r. $\beta_{g}$ :

$$
\begin{aligned}
& \beta_{g} / \beta_{0}=1- \\
& \frac{v_{x} f\left(v_{x}\right) \cdot F^{-2}\left(v_{x}\right)+v_{y} g\left(v_{y}\right) G^{-2}\left(v_{y}\right)+v_{z} g\left(v_{z}\right) G^{-2}\left(v_{z}\right)}{\left[F\left(v_{x}\right)\right]^{-1}+\left[G\left(v_{y}\right)\right]^{-1}+\left[G\left(v_{z}\right)\right]^{-1}-2}
\end{aligned}
$$

which constitutes the reduced form of Eq. (22) in the limit of very large $v$. We then represent the grainboundaries and external surface effects on the polycrystalline film t.c.r. in the standard form $\beta_{F p} / \beta_{g}$ e.g. 


$$
\begin{aligned}
\beta_{F p} / \beta_{g} & =\left\{1-\frac{1}{M\left(v_{x}, v_{y}, \alpha\right)} \cdot\left[\frac{v_{x} f\left(v_{x}\right)}{F^{2}\left(v_{x}\right)}+\frac{v_{y} g\left(v_{y}\right)}{G^{2}\left(v_{y}\right)}\right.\right. \\
& \left.\left.+\frac{\alpha g(\alpha)}{G^{2}(\alpha)}\right]\right\} \times\left\{1-\left(\frac{v_{x} f\left(v_{x}\right)}{F^{2}\left(v_{x}\right)}+\frac{v_{y} g\left(v_{y}\right)}{G^{2}\left(v_{y}\right)}\right.\right. \\
& \left.+\frac{v_{z} g\left(v_{z}\right)}{G^{2}\left(v_{z}\right)}\right)\left[F^{-1}\left(v_{x}\right)+G^{-1}\left(v_{y}\right)+G^{-1}\left(v_{z}\right)\right]^{-1}
\end{aligned}
$$

\section{DISCUSSION}

In the three dimensional model it was assumed that the grain size exhibited cubical shape with equal values for the grain sizes $a_{i}$ measured in the $x$-, $y$ - and $z$-directions (i.e. $v_{x}=v_{y}=v_{z}$ ).

Under this condition the exact expression for the film conductivity ${ }^{3}$ was:

$$
\sigma_{F p} / \sigma_{0}=\frac{3}{2 b}\left\{\kappa-\frac{1}{2}+\left(1-\kappa^{2}\right) \ln \left(1+\kappa^{-1}\right)\right\}
$$

with

$$
\begin{aligned}
& b=\mu^{-1}+v(1-C), \quad C=4 / \pi \\
& \kappa=b^{-1}\left[1+C^{2} \cdot v^{-1}\right]
\end{aligned}
$$

and then the film t.c.r. was found to be: ${ }^{3}$

$$
\beta_{F p} / \beta_{0}=\frac{1}{b} \frac{\kappa^{-1}-2+2 \kappa \ln \left(1+\kappa^{-1}\right)}{\kappa-\frac{1}{2}+\left(1-\kappa^{2}\right) \ln \left(1+\kappa^{-1}\right)}
$$

In the limit infinitely thick fine-grained films the preceding equation reduces to

$$
\beta_{g} / \beta_{0}=\frac{v}{1-C} \frac{\xi^{-1}-2+2 \xi \ln \left(1+\xi^{-1}\right)}{\xi-\frac{1}{2}+\left(1-\xi^{2}\right) \cdot \ln \left(1+\xi^{-1}\right)}
$$

with

$$
\xi=\left(v+C^{2}\right) \cdot[1-C]^{-1}
$$

From Eqs. (28) and (29) the exact value of the t.c.r. ratio $\beta_{F p} / \beta_{g}$ is then easily deduced.

It must be pointed out that when the effect of grain-boundary scattering becomes negligible (i.e. when $\left(v_{i} \rightarrow \infty\right)$ the functions $G\left(v_{i}\right)$ and $F\left(v_{i}\right)$ tend to unity whereas the functions $g\left(v_{i}\right)$ and $f\left(v_{i}\right)$ approach zero. As in the limit of very large $v$ the $G(\alpha)$ and $g(\alpha)$ functions respectively reduce to $G(\mu)$ and $g(\mu)$ we note that the present approximate method satisfies, as the three dimensional method, the physical requirement which states that when the grain-boundaries do not contribute to the resistivity Eqs. (13) and (22) simply become the following Cottey's relations: ${ }^{7}$

$$
\begin{aligned}
& \rho_{F p} /\left.\rho_{0}\right|_{v \rightarrow \infty} \approx \rho_{F} /\left.\rho_{0}\right|_{\text {Cottey }}=[G(\mu)]^{-1} \\
& \beta_{F p} /\left.\beta_{0}\right|_{v \rightarrow \infty} \approx \beta_{F} /\left.\beta_{0}\right|_{\text {Cottey }} \approx 1-\frac{\mu g(\mu)}{G(\mu)}
\end{aligned}
$$

\begin{tabular}{|c|c|c|c|c|c|c|c|c|c|c|}
\hline \multirow[b]{2}{*}{$\mu$} & \multicolumn{2}{|c|}{$v=0.4$} & \multicolumn{2}{|c|}{$v=1$} & \multicolumn{2}{|c|}{$v=2$} & \multicolumn{2}{|c|}{$v=4$} & \multicolumn{2}{|c|}{$v=10$} \\
\hline & $\begin{array}{l}\text { Exact } \\
\text { values }\end{array}$ & $\begin{array}{l}\text { Approx. } \\
\text { values }\end{array}$ & $\begin{array}{l}\text { Exact } \\
\text { values }\end{array}$ & $\begin{array}{l}\text { Approx. } \\
\text { values }\end{array}$ & $\begin{array}{l}\text { Exact } \\
\text { values }\end{array}$ & $\begin{array}{l}\text { Approx. } \\
\text { values }\end{array}$ & $\begin{array}{l}\text { Exact } \\
\text { values }\end{array}$ & $\begin{array}{l}\text { Approx. } \\
\text { values }\end{array}$ & $\begin{array}{l}\text { Exact } \\
\text { values }\end{array}$ & $\begin{array}{l}\text { Approx. } \\
\text { values }\end{array}$ \\
\hline 0.01 & 0.03883 & 0.05265 & 0.04796 & 0.05765 & 0.05325 & 0.05964 & 0.05691 & 0.06072 & 0.05967 & 0.06140 \\
\hline 0.04 & 0.08585 & 0.11254 & 0.11656 & 0.13917 & 0.135657 & 0.15174 & 0.14907 & 0.15916 & 0.15934 & 0.16407 \\
\hline 0.1 & 0.12559 & 0.15696 & 0.18611 & 0.21611 & 0.22576 & 0.24899 & 0.25487 & 0.26968 & 0.27761 & 0.28505 \\
\hline 0.4 & 0.17541 & 0.20529 & 0.29639 & 0.32695 & 0.38787 & 0.41324 & 0.46072 & 0.47848 & 0.52074 & 0.52982 \\
\hline 1 & 0.19340 & 0.22108 & 0.34686 & 0.37351 & 0.47300 & 0.49433 & 0.57930 & 0.59394 & 0.67054 & 0.67796 \\
\hline 4 & 0.20458 & 0.23053 & 0.38281 & 0.40536 & 0.53976 & 0.55584 & 0.64092 & 0.65278 & 0.75205 & 0.75777 \\
\hline 10 & 0.20741 & 0.23258 & 0.39132 & 0.41278 & 0.65654 & 0.57107 & 0.70566 & 0.71386 & 0.84097 & 0.84431 \\
\hline 40 & 0.20831 & 0.23362 & 0.39579 & 0.41666 & 0.56552 & 0.57916 & 0.71996 & 0.72727 & 0.86684 & 0.86387 \\
\hline 100 & 0.20856 & 0.23384 & 0.39670 & 0.41745 & 0.56736 & 0.58083 & 0.72292 & 0.73005 & 0.86533 & 0.86794 \\
\hline
\end{tabular}

For a comprehensive comparison of the exact and approximate expressions of film conductivity and t.c.r. we give in Tables I, II and III the numerical results related to the conductivity ratio $\sigma_{F p} / \sigma_{0}$ and to the t.c.r. ratios $\beta_{F p} / \beta_{0}$ and $\beta_{F p} / \beta_{g}$ respectively, obtained from the exact three dimensional model equations (Eqs. (25) (28) and (29)) and from the

TABLE I

Comparison of the exact and approximate values of the conductivity ratio $\sigma_{F p} / \sigma_{0}$ (as given by respective Eqs. (25) and (13)). 
TABLE II

Exact and approximate values (as given by respective Eqs. (28), (29), (22) and (24)) of the t.c.r. ratios $\beta_{F p} / \beta_{0}$ and $\beta_{F p} / \beta_{g}$ for $\nu=0.4$.

\begin{tabular}{rlllll}
\hline & \multicolumn{3}{c}{$\beta_{F p} / \beta_{0}$} & & $\beta_{F p} / \beta_{g}$ \\
\cline { 2 - 3 } \cline { 5 - 6 }$\mu$ & $\begin{array}{l}\text { Approximate } \\
\text { values }\end{array}$ & $\begin{array}{l}\text { Exact } \\
\text { values }\end{array}$ & & $\begin{array}{l}\text { Approximate } \\
\text { values }\end{array}$ & $\begin{array}{l}\text { Exact } \\
\text { values }\end{array}$ \\
\hline 0.1 & 0.267216 & 0.134500 & 0.909681 & 0.643565 \\
0.2 & 0.276613 & 0.157221 & & 0.941670 & 0.752285 \\
0.4 & 0.283279 & 0.176419 & 0.964362 & 0.844145 \\
0.8 & 0.287730 & 0.190176 & & 0.979514 & 0.90997 \\
1 & 0.288773 & 0.193448 & 0.983066 & 0.925625 \\
2 & 0.291074 & 0.200668 & 0.990900 & 0.960172 \\
4 & 0.292357 & 0.204674 & 0.995268 & 0.979341 \\
8 & 0.293039 & 0.206791 & 0.997588 & 0.989473 \\
10 & 0.293179 & 0.207225 & 0.998064 & 0.991546 \\
20 & 0.293462 & 0.208101 & & 0.999028 & 0.995741 \\
40 & 0.293606 & 0.208545 & 0.999517 & 0.997862 \\
80 & 0.293678 & 0.208768 & & 0.999763 & 0.998929 \\
100 & 0.293692 & 0.208812 & 0.999812 & 0.999143 \\
\hline
\end{tabular}

approximate equations (Eqs. (13) (22) and (24)) in which we have assumed $v_{x}=v_{y}=v_{z}=v$. Table I shows that the approximate values of the conductivity lead to discrepancies even for large thickness when the $v$ parameter takes small values, whereas for $v>0.4$ the approximate values deviate from the exact values, by only $10 \%$ until the $\mu$ parameter keeps values greater than 0.1 . This feature is not surprising because grain-boundary scattering becomes predominant for small $v$ and the validity of Matthiessen's rule is then altered as suggested earlier. ${ }^{6}$ But since this feature is essentially due to inaccuracies in the grain-boundaries terms of the present model thus we may expect less significant resultant deviations between exact and approximate equations by considering $\beta_{F p} / \beta_{g}$ the reduced t.c.r. related to the t.c.r., $\beta_{g}$ of an infinitely thick film instead of the usual $\beta_{F p} / \beta_{0}$ ratio. Table II clearly shows that the $\beta_{F p} / \beta_{0}$ ratio exhibits larger discrepancies than the $\beta_{F p} / \beta_{g}$ ratio. As this behaviour is typical of small $v$ Table II represents only the results for $v=0.4$ but it is interesting to note that for increasing values of $v$ the discrepancy decreases; for example for $v=2$, and $\mu=0.4$ we obtain deviations of about $17 \%$ for the t.c.r. ratio $\beta_{F p} / \beta_{0}$ and of about $11 \%$ for the $\beta_{F p} / \beta_{g}$ ratio.

Furthermore Table III indicates that the approximate model leads to reasonable deviations (less than about $10 \%)$ in a relatively large $\mu$ range $(\mu>0.4)$ provided that the grain parameter $v$ remains larger than 0.4 as previously observed for the conductivity ratio.

As at room temperature the films may be regarded as continuous ${ }^{1-18}$ in this defined $\mu$ parameter range the approximate Eqs (13) (22) and (24) generally remain satisfying to represent the thickness variations of the t.c.r.

\section{CONCLUSION}

As it must be kept in mind that to perform the calculation of the strain coefficient ${ }^{1,16,19,20}$ we have to undertake a logarithmic differentiation of the approximate expression of the film resistivity it is reasonable to expect, in the light of the preceding discussion, the present approximate model to constitute a convenient form for describing the effects that thickness and grain-boundaries have on the coefficient of resistivity.

The effect of thermal strains ${ }^{21}$ on the t.c.r. could also be examined from this three dimensional point of view.

Comparison of experimental data on polycrystalline film strain coefficients of resistivity $\gamma_{F p}$ with the theoretical predictions deduced from the present

TABLE III

Comparison of the exact and approximate values of the t.c.r. ratio $\beta_{F p} / \beta_{g}$.

\begin{tabular}{|c|c|c|c|c|c|c|c|c|}
\hline \multirow[b]{2}{*}{$\mu$} & \multicolumn{2}{|l|}{$\nu=1$} & \multicolumn{2}{|l|}{$\nu=2$} & \multicolumn{2}{|l|}{$\nu=4$} & \multicolumn{2}{|l|}{$\nu=10$} \\
\hline & $\begin{array}{l}\text { Exact } \\
\text { values }\end{array}$ & $\begin{array}{l}\text { Approx. } \\
\text { values }\end{array}$ & $\begin{array}{l}\text { Exact } \\
\text { values }\end{array}$ & $\begin{array}{l}\text { Approx. } \\
\text { values }\end{array}$ & $\begin{array}{l}\text { Exact } \\
\text { values }\end{array}$ & $\begin{array}{l}\text { Approx. } \\
\text { values }\end{array}$ & $\begin{array}{l}\text { Exact } \\
\text { values }\end{array}$ & $\begin{array}{l}\text { Approx. } \\
\text { values }\end{array}$ \\
\hline 0.1 & 0.54556 & 0.738807 & 0.496116 & 0.620245 & 0.465644 & 0.538464 & 0.343879 & 0.374849 \\
\hline 0.4 & 0.763006 & 0.872977 & 0.712126 & 0.792932 & 0.676898 & 0.739373 & 0.650949 & 0.674640 \\
\hline 1 & 0.872999 & 0.934022 & 0.83929 & 0.885646 & 0.811757 & 0.842633 & 0.790106 & 0.805182 \\
\hline 4 & 0.962582 & 0.980230 & 0.949132 & 0.963846 & 0.937764 & 0.948065 & 0.928131 & 0.933379 \\
\hline 10 & 0.984474 & 0.991740 & 0.978494 & 0.984679 & 0.973304 & 0.977719 & 0.968839 & 0.971115 \\
\hline 40 & 0.996034 & 0.997890 & 0.994455 & 0.996049 & 0.993070 & 0.994216 & 0.99100 & 0.992462 \\
\hline 100 & 0.998407 & 0.999153 & 0.997821 & 0.998408 & 0.997206 & 0.997668 & 0.996774 & 0.996962 \\
\hline
\end{tabular}


model then seems possible provided that the comparison is carried out in the reduced form $\gamma_{F p} / \gamma_{g}$ where $\gamma_{g}$ is the strain coefficient of an infinitely thick film. These relatively long calculations will be reported in a future paper.

\section{REFERENCES}

1. C. R. Pichard, C. R. Tellier and A. J. Tosser, J. Mater. Sci., 15, 2991 (1980).

2. C. R. Pichard, C. R. Tellier and A. J. Tosser, Thin solid Films, 62, 189 (1979).

3. C. R. Tellier, C. R. Pichard and A. J. Tosser, Le Vide, $196 \mathrm{~S}, 193$ (1979).

4. C. R. Pichard, C. R. Tellier and A. J. Tosser, Phys. Stat. Solidi (B), 99, 353 (1980).

5. C. R. Tellier, C. R. Pichard and A. J. Tosser, Thin Solid Films, 61, 349 (1979).

6. J. M. Ziman, Electrons and Phonons, Oxford University Press (London) (1962).

7. A. A. Cottey, Thin Solid Films, 1, 297 (1967-1968).

8. E. H. Sondheimer, Adv. Phys., 1, 1 (1952).
9. C. R. Pichard, C. R. Tellier, A. J. Tosser, Le Vide, 35, 207 (1980).

10. C. R. Tellier and A. J. Tosser, Thin Solid Films, 44, 141 (1977).

11. See for example K. L. Chopra, Thin Film Phenomena McGraw Hill (New York), (1969).

12. C. R. Tellier and A. J. Tosser, Thin Solid Films, 52, 53 (1978).

13. C. R. Tellier and A. J. Tosser, Thin Solid Films, 37, 204 (1976).

14. K. L. Chopra, L. C. Bobb and M. H. Francombe, J. Appl. Phys., 34, 1699 (1963).

15. B. Laville Saint-Martin, Thin Solid Films, 6, 359 (1970).

16. C. Reale, Czech. J. Phys., B, 21, 662 (1971).

17. M. Adamov, B. Perovic and T. Nenadovic, Thin Solid Films, 24, 89 (1974).

18. R. Suri, A. P. Thakoor and K. L. Chopra, J. Appl. Phys., 46, 2574 (1975)

19. C. R. Tellier and A. J. Tosser, Electrocomp. Sci. Technol., 4, 9 (1977)

20. see for example G. R. Witt, Thin Solid Films, 22, 133 (1974).

21. C. R. Pichard, C. R. Tellier and A. J. Tosser, J. Phys. D: Appl. Phys., 13, 1325 (1980). 

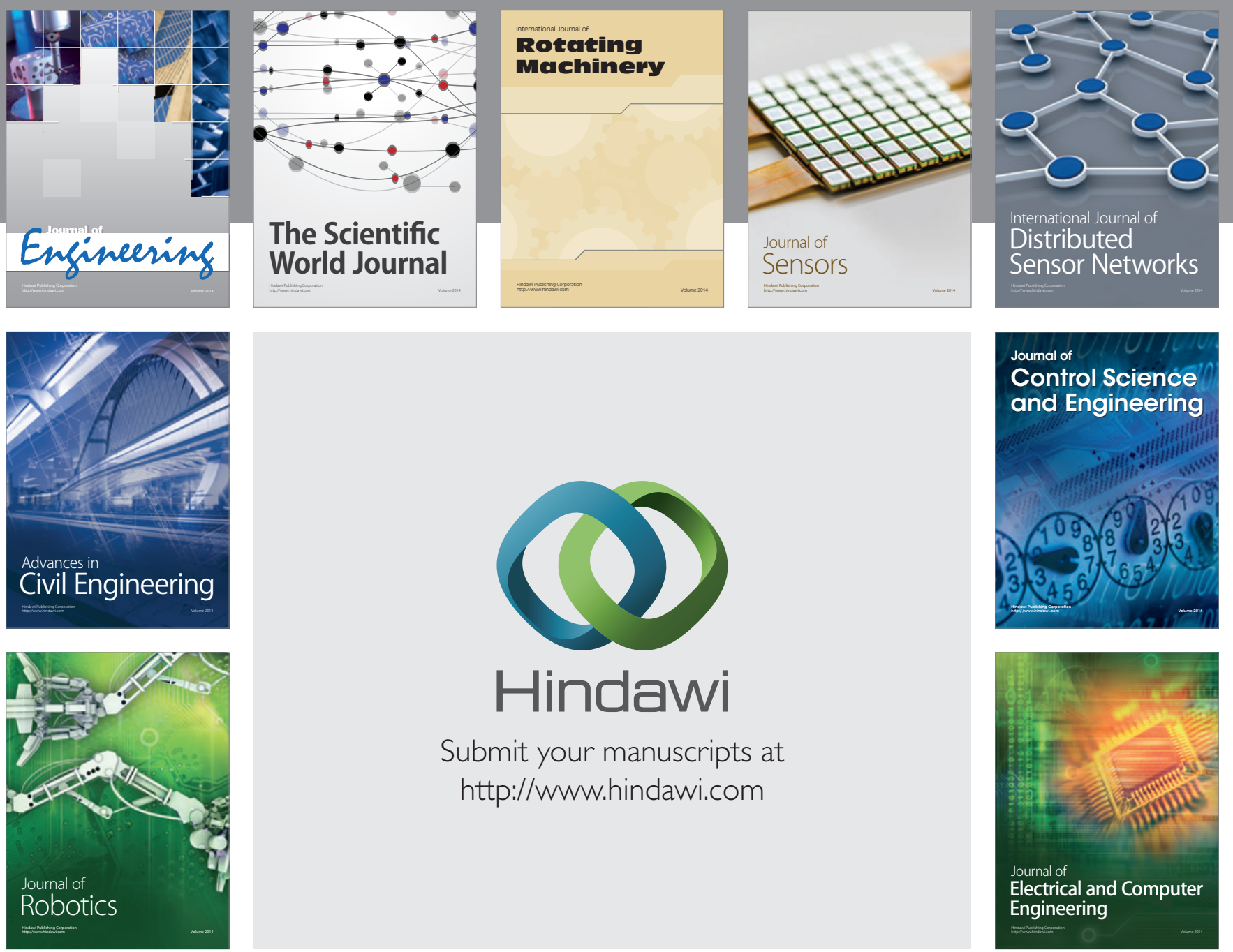

Submit your manuscripts at

http://www.hindawi.com
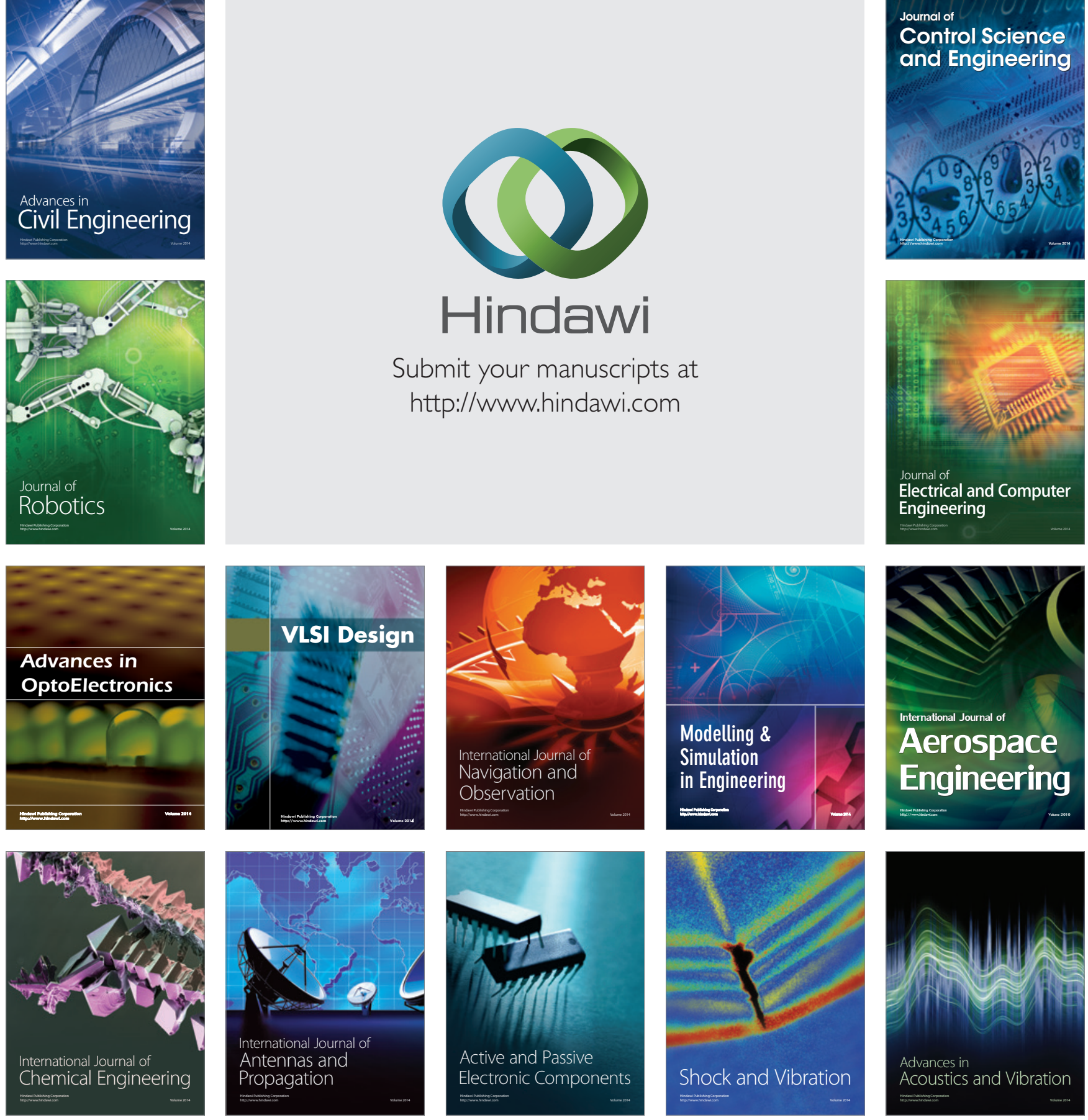